\title{
INFANCIAS VULNERADAS EN LAS GUERRAS CIVILES DE ESPAÑA Y GUATEMALA. UNA REVISIÓN DESDE EL CINE
}

\author{
Childhood Injured in the civil wars of Spain and Guatemala. A Revision from the Cinema
}

\author{
Otto Roberto Yela Fernández ${ }^{1}$ \\ Universidad de Alcalá de Henares \\ ottoyela@hotmail.com
}

Fecha de recepción: 28-II-2013

Fecha de aceptación: 10-III-2013

\begin{abstract}
RESUMEN: Todo conflicto armado vulnera las vidas de seres inocentes que, sin culpa alguna sufren las consecuencias físicas y psicológicas de los mismos. En las guerras civiles de España y Guatemala, los niños que murieron o resultaron heridos se contaron por miles, y toda una generación que vivió su infancia en ese contexto estuvo marcada por sus secuelas. En las últimas décadas, el cine ha recuperado muchas vivencias de esas realidades, que pueden ser motivo de reflexión histórica y educativa para las nuevas generaciones. El presente estudio responde a los siguientes interrogantes: ¿Puede el cine contribuir a recuperar la memoria histórica? ¿Cuáles son los imaginarios que recrea en torno a la infancia en tiempos de guerra civil? ¿Cómo se consigue que determinados hechos adquieran sentido para los espectadores, sobre todo en aquellos que no han vivido tales experiencias de manera directa? ¿Puede todo esto contribuir a los aprendizajes de las nuevas generaciones, especialmente de índole histórica? En este estudio se analizan las películas que se refieren a las guerras civiles de España y Guatemala, por ser parte de una tesis doctoral que el autor desarrolla en la Universidad de Alcalá, en la que se hace un estudio comparado al respecto.
\end{abstract}

Palabras clave: Cine, historia, educación, Guerra Civil española, Conflicto Armado Interno guatemalteco.

1 Profesor investigador, Licenciado en Comunicación por la Universidad de San Carlos de Guatemala, candidato a Doctor en la Universidad de Alcalá, título de tesis: «El cine como laboratorio sociohistórico y sus implicaciones educativas, estudio comparativo entre España y Guatemala»; Máster en Comunicación por la Universidad Iberoamericana, México, con énfasis en sociología y comunicación. 
АвSTRACT: All armed conflict violates the lives of innocent people who, through no fault suffer physical and psychological consequences thereof. In the civil wars in Spain and Guatemala, children who were killed or wounded were counted by thousands, and a generation who lived his childhood in that context was marked by its aftermath. In recent decades, the film has recovered many experiences of these realities, it can be a matter of historical reflection and education for new generations. This study answers the following questions: Can cinema help to recover the historical memory? What are the imaginary recreated around children in times of civil war? How does that certain facts acquire meaning for viewers, especially those who have not lived through such experiences directly? Can all this contribute to the learning of new generations, especially of a historical matter? Films that are addressed relate to the civil wars in Spain and Guatemala for being part of a doctoral thesis that the author developes at the University of Alcalá, which is a comparative study on the matter.

Keywords: Cinema, History, education, Spanish Civil War, Guatemalan Internal Armed Conflict.

\section{INTRODUCCIÓN}

Derivado del latín vulnerare, el término «vulnerar» equivale a "transgredir, quebrantar o herir» (DRAE, 2010). Durante las guerras civiles de España y Guatemala (como en todo conflicto armado), se cometieron muchas injusticias con un sinnúmero de víctimas. Bajo el fuego cruzado, y sin culpa alguna, una de las poblaciones más golpeadas fue la infantil, ya que por su dependencia del mundo adulto, se hallaron más vulnerables que el resto de la población. Históricamente, esa infancia fue transgredida, quebrantada, vulnerada.

El drama que tocó vivir a los niños en estas guerras, ha sido llevado a la pantalla en diversas películas. Estas constituyen valiosas referencias para reflexionar, a la luz de la historia y las ciencias sociales, sobre cómo esas infancias fueron violentadas en su derecho a la vida y al bienestar. Igual de importante resulta también, la tarea de examinar cómo se recrean en el cine, las estrategias de supervivencia que pusieron en práctica aquellos niños, en un intento de salvaguardar su integridad física y psicológica.

El presente estudio responde a las siguientes interrogantes: ¿Puede el cine contribuir a recuperar la memoria histórica? ¿Cuáles son los imaginarios que recrea en torno a la infancia en tiempos de guerra civil? ¿Cómo consigue que determinados hechos adquieran sentido para los espectadores, sobre todo en aquellos que no han vivido tales experiencias de manera directa? ¿Puede todo esto contribuir a los aprendizajes de las nuevas generaciones, especialmente de índole histórica?

Se abordan en este sentido las películas que hacen referencia a las guerras civiles de Espańa y Guatemala por ser parte de una tesis doctoral que el autor desarrolla en la Universidad de Alcalá, en la que se hace un estudio comparado al respecto. 


\section{LA REPRESENTACIÓN DE LA HISTORIA EN LAS IMÁGENES DE LOS NIÑOS DEL CINE DE GUERRA}

La infancia es (o debería ser), la etapa más feliz de la vida del ser humano. En los países que gozan de relativa estabilidad económica y política, los niños se convierten en el tesoro más preciado, puesto que en ellos descansa la esperanza de ver materializado el éxito y las oportunidades de las sociedades que buscan lograr la libertad y el bienestar individual y público. Sin embargo, en tiempos de guerra, esos ideales se ven truncados, y cambiados por su crueldad y falta de respeto por la vida.

Si las historias personales de las víctimas de guerra se caracterizan por reflejar las heridas físicas y psicológicas, cuanto más en el caso de los niños. Puesto que sus cuerpos y mentes están aun en etapa de desarrollo, es más difícil para ellos encontrar por sí mismos los mecanismos de acción que les permitan eludir las penurias, privaciones y al final, los traumas de la guerra.

Es importante aclarar que el papel que juega el cine en el tema de la infancia y la guerra, puede examinarse por lo menos desde dos perspectivas. La primera será la manera en que los nińos son representados en las películas, los roles que les son asignados, sus vivencias, etc. Esta faceta del cine puede ser analizada a la luz de la semiótica y de la historia, entre otras ciencias.

Una segunda perspectiva busca explorar el impacto que tienen los significados del cine en los infantes. Es decir que nos podemos ocupar de establecer la conveniencia de la utilización del cine en los ámbitos formativos en donde podamos aprovechar sus múltiples recursos en la tarea de brindar a los niños actuales las imágenes de realidades trágicas que ha tocado vivir a otras generaciones, cómo las han tenido que afrontar y, eventualmente, llegar a resolver. Por su naturaleza, esta segunda perspectiva puede ser abordada desde una postura educativa.

En las últimas dos décadas, incluso en las películas que tienen como argumento la Guerra Civil Española, han cambiado los protagonistas adultos por otros más jóvenes ( $E l$ laberinto del Fauno, La lengua de las mariposas, El viaje de Carol, etc.). Ibáñez lo explica así: «El perfil adulto de las películas de la Transición da paso a un cine que se ajusta a la importancia que ha cobrado la juventud en las sociedades contemporáneas (no solo ante las taquillas), y son los jóvenes y los adolescentes los protagonistas de las narraciones». Para el autor citado, esto responde a una «estrategia que combina las ambiciones lógicas de los productores del filme con el deseo de actualizar la memoria de unos hechos, muchos de ellos reales o basados en hechos reales, que tienden a difuminarse con el paso del tiempo» (Ibáñez, 2010, p. 92).

Según este autor, en las últimas dos décadas de producción cinematográfica que tienen que ver con la Guerra Civil espańola, se ha evolucionado hacia un «modelo de 
representación», en el que los protagonistas son mayoritariamente jóvenes y adolescentes, que «se rebelan y apuestan de manera activa por un compromiso con la libertad». Este modelo afecta a «la crisis del discurso histórico de la modernidad», por cuanto se opone a la idea modernista de poder situar «en un único lugar común y compartido la interpretación de la Historia, conforme a un proyecto lineal de progreso". Por otro lado, el nuevo cine fomenta el debate sobre si la cultura popular puede contribuir a la "construcción del conocimiento y la formación ideológica de la conciencia», es decir, si puede ser «fuente social de conocimiento histórico» (Ibáńez, 2010, p. 93).

En lo que toca al Conflicto Armado Interno guatemalteco, encontramos que de manera similar al caso español, algunas cintas de ficción emplean la figura de niños (como el caso de El silencio de Neto), y de jóvenes víctimas primarias o secundarias de la guerra (los casos de Ixcán y La hija del puma), o bien jóvenes combatientes de alguno de los frentes (Las Cruces).

Respecto de la imagen que los medios le atribuyen a la infancia, encontramos que cada vez más, las películas retratan con mayor detalle los sucesos históricos que rodean la narrativa. Esto las convierte en genuinas referencias de las costumbres, indumentarias, e incluso de las particulares relaciones interpersonales que existían en épocas anteriores, por ejemplo las que regían el trato entre padres e hijos. Ya lo dice García:

Existen películas que se han convertido en fuentes de documentación sociológica de la época en que fueron realizadas. En ellas se muestran a los niños tal cual eran en ese momento... son películas que aun siendo de ficción retratan con una enorme fuerza expresiva la realidad, y es esta la que se escapa por los intersticios de la ficción textual (García, 2000a, p. 10).

García (2000a), señala que los directores de cine intervienen directamente en el guión, incluyendo o excluyendo figuras infantiles, según convengan al desarrollo de la trama:

Los nińos están cuando deben estar, cuando son necesarios para la trama o cuando ellos, como personajes principales o secundarios organizan en un punto a lo largo de todo el texto (toda la película), el significado del relato, la economía cinematográfica agudiza la selección de la imagen. Y solo ve por el agujero del sentido (García, 2000a, p. 10).

Podemos decir entonces, que el historiador, el educador y el comunicador, pueden hacer suya la tarea reflexiva a partir de los medios informativos. De esta forma, lograr una alianza que busque orientar, y evitar dejar a la deriva el maremágnum de noticias, testimonios, recuerdos, que sobre los hechos pasados invaden los mass media. Ni la 
escuela ni la ciencia pueden pasar por alto las nuevas formas de establecer esos imaginarios colectivos que hoy circulan por los medios antes que por la gente, y como opina de los Reyes (2011), ambos, historiador y educador deben estar atentos a los discursos que se generan en los medios, y partir de ellos para contrastar los otros instrumentos científicos de investigación histórica.

\section{LOS IMAGINARIOS COLECTIVOS DE LA INFANCIA RECREADOS POR EL CINE}

De los Reyes (2011), Sánchez-Biosca (2006) y Ferro (2008), coinciden en la apreciación de que el cine (junto con los demás medios de comunicación), está configurando cada vez más los mapas referenciales a los que acuden las nuevas generaciones, cuando oyen mencionar instancias u objetos que no han tenido oportunidad de conocer en persona (las pirámides de Egipto por ejemplo), o bien que son elementos de su vida cotidiana, que se encuentran «etiquetados» de alguna manera por su entorno social.

De los Reyes (2011), indica que el cine, al igual que otros medios informativos, tiene la capacidad de alimentar un imaginario en la mente de los espectadores, de manera tal que los hechos que exhibe son tomados por el público, a quien no interesa la veracidad de los mismos, sino que se conforma con verlos o escucharlos. Según el experto, las imágenes que brinda el cine, quedan en la memoria de los niños y jóvenes, hasta el punto de que, por ejemplo, para hablar de los egipcios, los profesores de niños pequeños primero tienen que «descartar los estereotipos falsos que los infantes manejan de tal o cual historia: las momias, las maldiciones, el misterio, etc. Al nińo hay que enseñarle que la realidad tiene muchos matices", liberarlo de los mitos comerciales sin fundamento histórico. Pese a ello, el profesor tiene mucho que aprovechar de tal imaginario, ya que la mayoría de lugares históricos son abordados en los medios, y al llegar a la escuela, los niños ya tienen ciertos conocimientos que tomarían más tiempo enseñárselos, de no ser por las películas que los mencionan.

Un ejemplo del empleo de los imaginarios en las películas de la Guerra Civil española, lo constituye La hora de los valientes (1998), en donde uno de los recursos icónicos utilizados por el director (Antonio Mercero), es el paralelismo que hace entre la Guerra de Independencia de España y la Guerra Civil, a través del lienzo en el cual Goya representa a los fusilados del Dos de Mayo. En la película, este cuadro, que era el favorito de Manuel (el joven celador del Museo del Prado que defiende su patrimonio incluso con su vida), se convierte en metáfora de la recreación en escena del propio fusilamiento del protagonista, en circunstancias parecidas de defensa de un ideal de libertad. Además, las ambientaciones del filme (decorados, escenografía, vestuario, etc.), coinciden con las de la época de la Guerra Civil española, y dan la suficiente credibilidad a la película en general. El filme evoca las memorias de quienes sobrevivieron la guerra, pues lleva el 
título de uno de los eslóganes que más se oían por ese entonces en los aparatos de radio de Madrid: «la hora de los valientes» (Crusells, 2006, p. 304).

La idea del imaginario colectivo que recrean los medios es compartida por Sánchez-Biosca (2006a, p. 317), quien indica que se generan a partir de un «sistema complejo de canales interconectados». Este autor lo define como la «memoria colectiva del pasado reciente», por ejemplo, de los sucesos traumáticos de la Guerra Civil española. Al igual que de los Reyes, Sánchez-Biosca advierte de la diferencia que existe entre lo que se ha "cristalizado en imágenes y relatos verosímiles de la guerra y aquello que los estudiosos especializados establecen en el ámbito del conocimiento histórico», en clara alusión a la diferencia entre memoria e historia.

Monterde (1986, p. 45), coincide con de los Reyes (2011), Sánchez-Biosca (2006a) y Ferro (2008), en indicar que el medio cinematográfico contribuye a la creación de imaginarios colectivos, puesto que "constituye un receptáculo de las mentalidades, de los mitos y representaciones colectivas».

Un ejemplo de ello lo constituye tanto la película, como la obra teatral de nombre Las bicicletas son para el verano (1984), las cuales representaron las vivencias de un preadolescente durante el sitio franquista de Madrid, en donde Fernán Gómez (como director), tuvo la capacidad de describir lo que los madrileńos vivieron y sufrieron, y que hasta entonces pudieron contemplar en escena sin preocuparse por aprobar de antemano tal o cual ideología, sino más bien limitándose a ser el reflejo de vivencias que hubieron de callar por muchos años. Las bicicletas son para el verano constituye así un ejemplo de cómo un filme puede llegar a constituir una suerte de imaginario colectivo (Monterde, 1986, p. 177).

Los medios siempre han estado interesados en los temas nostálgicos que atrapan al público en la evocación de sus memorias, tanto a nivel privado (las vivencias familiares), como a nivel colectivo (España o Guatemala como país, según sea el caso). Prueba de ello fue la gran acogida que tuvo la obra teatral primero, y luego la película mencionada Las bicicletas son para el verano (1984). Su éxito dramático lo constituye la singular presentación del pensamiento del padre frente a la Guerra Civil española, todo ello visto y relatado a través de los ojos de un preadolescente que al inicio de su vida afectiva se ve envuelto en hechos trágicos que amenazan la integridad psíquica y física de toda su familia. Las actuaciones dentro del filme son tan buenas como lo fueron en su antecesora versión teatral, de hecho el actor principal, que interpreta al padre (Agustín González), es el mismo en ambas versiones.

Desde siempre, el cine ha contribuido a la recuperación de la memoria. Esto lo vemos en la siguiente apreciación de Payán sobre la película en cuestión: 
Figura 1. Cartel de Las bicicletas son para el verano (1984).

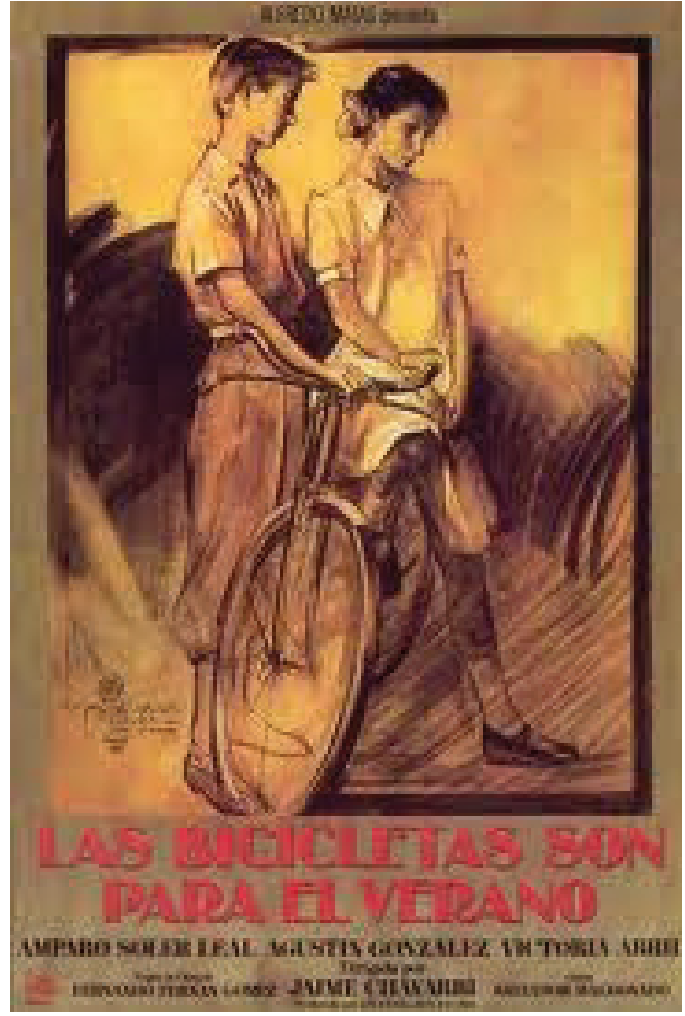

Tras convencer al padre de comprarle una bicicleta, las aspiraciones de Luisito se ven frustradas por el estallido de la Guerra Civil española, y desde ese momento la bicicleta ya no es su mayor preocupación. Su vida cotidiana cambia radicalmente, y su familia entera va a verse afectada por el sitio de Madrid y los incesantes bombardeos franquistas. Por las calles y en el interior de cada casa se respira la escasez, el peligro y sobre todo el miedo (Payán, 2006, p. 30).

En palabras de Gubern (1986, p. 170), Las bicicletas son para el verano es una "crónica intimista, con pinceladas de humor y de dramatismo de familias de la clase media que viven sus historias personales en Madrid durante la Guerra Civil». Al buen desempeño interpretativo de los actores de la obra fílmica, se suma la atinada caracterización contextual que la película va relatando a partir de noticias, hechos y elementos históricos que van reconstruyendo el escenario de una ciudad destruida de forma material y debilitada anímicamente tras el sitio y bombardeo continuados de varios ańos. Todo ello es actualizado por el director a partir de los diálogos cotidianos de los personajes, en donde afloran las preocupaciones por la comida que no alcanza, o el destino de cada cual tras la guerra, por ejemplo. 


\section{LA BÚSQUEDA DEL SENTIDO HISTÓRICO A TRAVÉS DEL ANÁLISIS FílMICO}

El cine constituye un medio interdisciplinar, atendiendo a la infinita diversidad de enfoques posibles de ser trabajado. El presente estudio se propone, entre otros objetivos, evaluar las posibilidades que brinda el cine de ficción para reflexionar sobre los temas socio-históricos que la escuela aborda en su cotidianeidad. En este apartado, se discutirán dichas posibilidades por parte de los expertos que han profundizado respecto del impacto que tiene el cine en la enseñanza (o la reflexión), histórica.

Monterde (1986), recomienda que, para analizar un filme en los contextos de educación e historia hay que establecer el punto de vista apropiado según los objetivos que se pretenden alcanzar con la actividad: decidir qué es lo que queremos y por tanto qué es lo pertinente a tomar de la historia o a seleccionar del filme. Posteriormente, existen dos etapas importantes para la crítica histórica del filme, como lo son la descripción y la producción de sentido.

Los cineastas tienen múltiples recursos a su disposición para magnificar los sentidos, y focalizar al espectador en determinados detalles que interesan destacar. Prueba de ello es la conocida escena de La lista de Schindler (1996), en donde Spielberg colorea a propósito el pequeño abrigo de una nińa que corre entre la multitud conducida hacia el exterminio nazi. García (2000b, p. 26), califica este recurso como un «señuelo para la mirada», "una retórica para alimentar la antítesis entre el rojo y el blanco y negro», recordemos que la película está filmada casi enteramente en tonos neutros de blanco y negro. Este autor considera ese recurso como «retórico», ya que «individualiza» a criterio del director en un caso específico lo que de manera natural era una experiencia colectiva masificada.

Sorlin (citado por Monterde), indica que el sentido fílmico no es una: «significación inherente al filme, sino que son las hipótesis de investigación las que permiten desvelar ciertos conjuntos significantes». Según esto, el sentido no está explícito en la película, sino que es producto de una producción posterior «fruto de la comprobación con los elementos suministrados por el filme». Por todo ello, Monterde deriva que el sentido del filme no tiene por qué ser único, ni tampoco permanece inmutable al paso del tiempo: «un mismo filme podrá decir cosas distintas a investigadores diferentes». Añadido a esto, y dado que todo filme tiene la vocación de brindar algún sentido a quien lo ve, el autor citado considera el proceso de análisis como un interrogatorio que efectúa el investigador al filme: «Sólo interrogándolo podremos producir nuestro propio sentido, y sólo en la producción de sentido encontrará la obra fílmica su justificación y plenitud» (Monterde, 1986, p. 25).

Para hallar los sentidos en un filme histórico, Ferro (2008, p. 6), indica que se deben tomar en cuenta «los puntos de referencia de las uniones y de las rupturas» del 
discurso con respecto a los sucesos históricos. De conseguir esto, podremos vehicular en el cine una importante herramienta de análisis, ya que contribuiría a:

La búsqueda del sentido que puede tener la evolución de las sociedades, el conocimiento de situaciones y acontecimientos pasados gracias a los archivos, a los testimonios, la demostración propiamente científica que trata más de analizar que de reconstruir el pasado, buscar el origen de los problemas de nuestro tiempo (Ferro, 2008, p. 6).

Sobre esta coherencia del discurso, tan apetecida por los espectadores a la hora de ver una película, se pronuncia el profesor valenciano Sánchez-Biosca (2006b, p. 13), quien opina que la historia «no son los hechos acontecidos en el pasado, es un discurso [un conjunto casi infinito de discursos], que trata [n], de explicarlos, conectarlos inscribiéndolos en cadenas causales que les otorgan sentido». El cine constituye uno de esos discursos, que se une a muchos otros habidos y por haber, que intenta (con intenciones diversas), explicar la historia.

El discurso cinematográfico puede que descanse en alguna visión ideológica de sus autores, que pretenden explicar la historia, o muchas otras veces, los autores acuden a hechos históricos de gran significado para la audiencia, tan solo con el objetivo de «conectar» con la "cadena de emociones y sentidos» que implica el cine (Amar, 2009, p. 39), y así conseguir mayor audiencia para sus productos.

Este sería el ejemplo de películas tales como El viaje de Carol (2002), pues el poco tiempo que se dedica en la cinta a sucesos relacionados directamente con la Guerra Civil, no da oportunidad al cuestionamiento crítico de los hechos históricos relacionados con ella; más bien se centra en la historia familiar de la joven Carol.

Para Ferro, en materia de recuperación de memoria e historia, los documentos fílmicos, cada vez más, ganan terreno sobre los escritos, puesto que "hoy en día, la inspiración de la imagen, del filme, toma el relevo a las formas escritas, a las que tiende a sustituirlas, apoyada por el poder de los medios de comunicación» (Ferro, 2008, p. 6).

Una de las circunstancias que en la actualidad determinan el uso del cine es su preferencia por las generaciones en edad educativa. Los jóvenes y niños que constituyen el principal grupo meta de la escuela, prefieren los medios audiovisuales modernos, al punto que los han adoptado como parte de su cotidianidad. Ferro (2008, p. 7), lo expresa así: "cada vez más la fuerza de la imagen consiste en sustituir a las demás manifestaciones que suscita el análisis del pasado. Por la hegemonía de Hollywood, en Francia se conoce más la conquista del Oeste, que las guerras napoleónicas o de Luis XIV».

El atractivo que ejercen los materiales fílmicos sobre los jóvenes podemos ejemplificarlo con El laberinto del Fauno (2006), película que según Ibáñez (2010), forma parte 


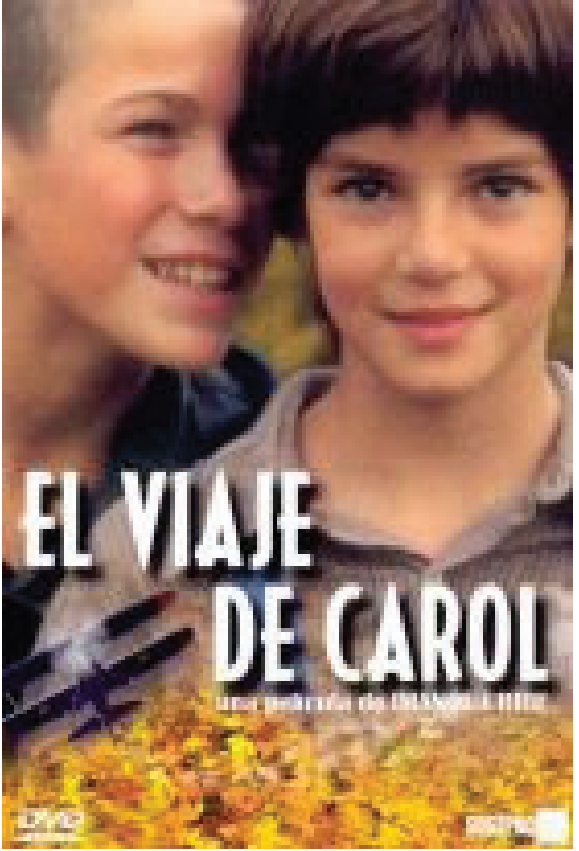

Figura 2. Cartel de El viaje de Carol (2002).

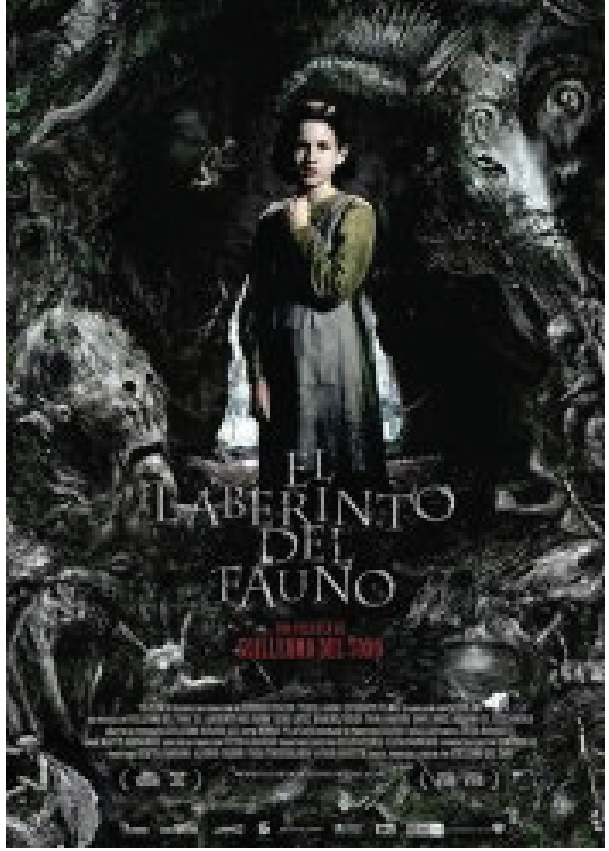

Figura 3. Cartel de El laberinto del Fauno (2006).

de un cine comprometido con la recuperación de la memoria histórica, pues plantea nuevos debates sobre los acontecimientos. Su argumento narrativo hace una relación entre los sucesos de la Guerra Civil espańola y la vida familiar de una nińa, que acude al mundo de la fantasía como escape y consuelo de una realidad adversa.

Esta película es rica en figuras cargadas de simbolismos, tanto de imágenes comunes del imaginario de los jóvenes, como monstruos y cuentos de hadas, así como también de figuras enigmáticas con trascendencia para la construcción del relato (la tiza como vector entre dos mundos, por ejemplo).

Marcel Martin (citado por Monterde), indica que el cine «produce o reproduce la ideología dominante en la medida en que su característica específica esencial, la impresión de realidad, no viene constituida por la reproducción de la realidad concreta, sino por el reflejo de las cosas refractadas por la ideología», "el cineasta que se cree libre filmando la realidad no es, así, más que el instrumento involuntario de la propagación de esa ideología». (Monterde, 1986, p. 45)

García (2000b, p. 10), se refiere a lo anterior indicando que «El cine no representa la realidad, la construye, y al construirla solo utiliza los elementos que precisa para darle el significado y el sentido preciso a ese nuevo mundo». Un ejemplo de esto puede 
constituir otra de las películas que vio la luz en este periodo: Las largas vacaciones del 36 (1976). La película aborda los acontecimientos de la guerra desde el lado republicano, sobre todo desde el punto de vista de las familias burguesas barcelonesas (la prolongación del descanso de los niños dio nombre al filme), que quedaron atrapadas por el conflicto en sus propiedades de veraneo en julio del 36. Gubern (1986, p. 168), explica que este filme perteneció al grupo de películas que vinieron tras el rompimiento de la mordaza franquista, y por ello fueron las primeras en ventilar aspectos críticos de la contienda nunca abordados hasta ese momento.

Raack (citado por Rosenstone, 1997), opina que «las imágenes son más apropiadas para explicar la historia que las palabras», pues la historia escrita convencional es tan lineal y limitada que es incapaz de mostrar el complejo y multidimensional mundo de los seres humanos. Rosenstone comparte la posición de Raack, y señala las especiales características contextuales del complejo ritual que envuelve asistir a la proyección de una película:

Las películas tienen más facilidad que los libros para hacernos partícipes de las vidas y situaciones de otras épocas. Las imágenes de la pantalla, junto con los diálogos y sonidos en general, nos envuelven, embargan nuestros sentidos y nos impiden mantenernos distanciados de la narración. En la sala de cine estamos por unas horas, atrapados en la historia (Rosenstone, 1997, p. 31).

\section{INFANCIAS VULNERADAS EN LA GUERRA CIVIL ESPAÑOLA}

A partir de los ejemplos señalados podemos ver que, dado el protagonismo de los niños actores, la utilización de sus historias se hace posible (incluso necesario), para fines educativos, en busca de la identificación de los espectadores con los roles y vivencias de los mismos, sobre todo porque rememora aquellos niños convertidos en héroes anónimos, al colaborar con las tareas familiares a pesar de las circunstancias adversas de la guerra.

Como consecuencia de la Guerra Civil española (y posterior a ella, para huir de la represión franquista), fueron miles los refugiados que se desplazaron en el territorio español y hacia muchos países extranjeros. Una película que habla al respecto es El otro árbol de Guernica (1969), a partir de las vivencias de los niños que fueron obligados a exiliarse por la guerra. Basada en la novela de Luis de Castresana, este relato autobiográfico retrata la aventura de dos niños vascos que son acogidos por hogares adoptivos en Bélgica. Estos infantes sufren malos tratos por sus compañeros, que los discriminan por su calidad de ser extranjeros y españoles. Este hecho fue visible en la vida real en numerosos campos de refugiados en Francia, donde se dieron casos lamentables de «incomprensión u hostilidad extranjera hacia España» (Gubern, 1986, p. 150). 


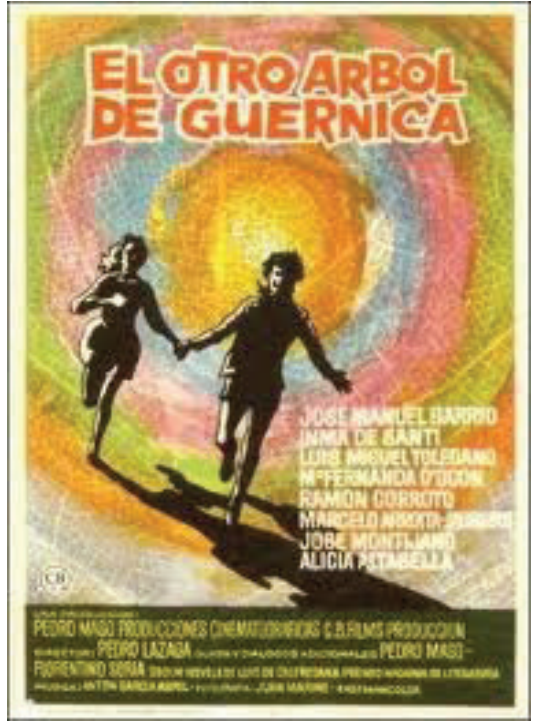

Figura 4. Cartel de El otro árbol de Guernica (1969).

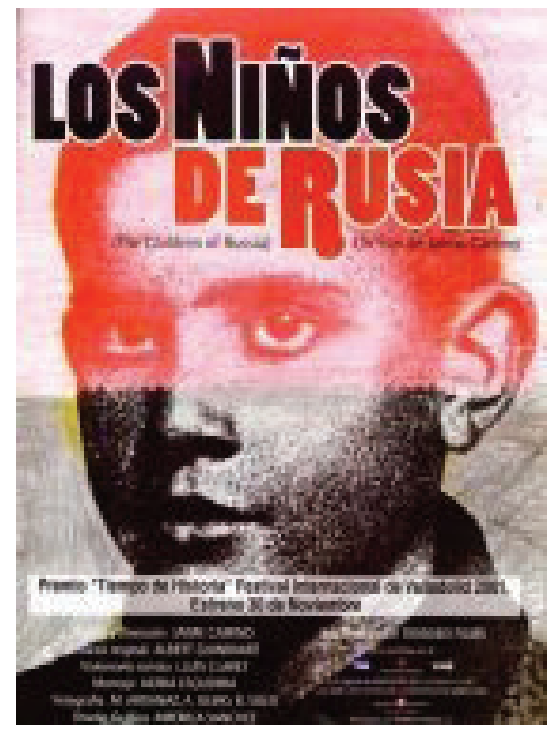

Figura 5. Cartel de Los niños de Rusia (2001).

Los niños de Rusia (2001), reúne los testimonios de quienes fueron trasladados en calidad de refugiados a Leningrado, Moscú y otras ciudades soviéticas, cuando en 1937 se decidió en la España republicana, proteger de los estragos de la guerra a los nińos, enviándolos al extranjero. Las conclusiones principales del filme de Jaime Camino hacen alusión a las secuelas que el desarraigo provocó en los cerca de 3.000 niños españoles que fueron embarcados a Rusia.

Uno de los daños que se les causó de por vida, según los testimonios expuestos por los entrevistados, fue el sentirse extranjeros en todas partes, pues en Rusia nunca dejaron de añorar la España abandonada de manera abrupta, y al regreso, después de casi 20 años, no pudieron hallar su lugar en una sociedad tan distinta a aquella que los acogió por tanto tiempo. Al final, atestiguan los afectados, que más de la mitad de aquellos niños devueltos adultos a su tierra natal, volvieron a dejar España con diferentes destinos (gran parte de ellos retornaron a Rusia), ahora de manera voluntaria y como consecuencia del mencionado sentimiento de desarraigo y de falta de pertenencia a un contexto español que les resultó ajeno (por condiciones religiosas, políticas, familiares, etc.).

De los 3.000 nińos que fueron expatriados, regresaron a España 1.500 aproximadamente. De ellos, la mitad retornó a la URSS porque «no se adaptó a la España franquista", y al comprobar que "después de veinte años, los sentimientos entre padres e hijos se habían quebrado por la larga ausencia». Los que se quedaron (aproximadamente 
800), sufrieron la desconfianza del franquismo, al asumirlos como agentes comunistas, sumado a que la CIA y el MI-6 británico interrogó a los que habían trabajado en «lugares de responsabilidades para averiguar secretos militares». Mientras que los que retornaron a la URSS fueron vigilados por la KGB por si eran agentes occidentales (Crusells, 2006, p. 313).

El cine cumple una función de recuperación de los hechos pasados, puesto que de no ser por el recurso audiovisual, sería muy difícil que las nuevas generaciones tomaran idea de las costumbres, las modas, los ambientes de los mismos. En La lengua de las mariposas son retratados muchos elementos característicos de las escuelas republicanas, en tanto que la película se desarrolla en los meses previos al alzamiento militar del 36. Prueba de ello son los pupitres utilizados en la cinta, similares a los empleados por la Institución Libre de Enseñanza en ese momento. El profesor ocupa el centro de interés de la película, pues se expone por ejemplo, la manera cómo se auxilia de la naturaleza (aprovechamiento de los recursos disponibles), para dar lugar a una educación significativa para niños que a diario se ven enfrentados al entorno natural, pero sin percatarse de los fenómenos que dan continuidad a la vida.

De ahí deriva el nombre de la película, de un ejemplo que pone el profesor mientras habla de la anatomía de los insectos, mientras que lleva a los alumnos a presenciar el evento en un entorno natural. Lo anterior es una muestra del aprendizaje significativo propiciado por un docente que, a pesar de estar cerca de su jubilación, se encuentra motivado para encontrar en eventos cotidianos, una oportunidad para el aprendizaje de sus alumnos. La pedagogía del profesor está basada en la Institución Libre de Enseñanza, en la independencia del Estado y de la Iglesia, defiende la idea de una educación sin ataduras ni opresiones.

Podemos ver así que, en La lengua de las mariposas se revisa el tipo de educación que promovió la II República, integrada a los eventos sociales e históricos del entorno. La educación de un niño se convierte en el hilo conductor de la historia que explica en parte el drama que tocó vivir a muchas familias, atrapadas en el «fuego cruzado» de la guerra.

Los girasoles ciegos (2009), retrata la frustración y angustia de las familias republicanas que tuvieron que mentir e inventar toda clase de estratagemas para ocultar su pasado ante la represión sistemática de la dictadura de posguerra. Retrata también el ambiente claustrofóbico que debe enfrentar el jefe del hogar, escondido en un recinto secreto de la casa. Se hace patente también la doble identidad que toca vivir a su hijo, aquel niño que enfrenta por un lado, el adoctrinamiento fascista en la escuela, y por el otro, las medidas de seguridad que, a fuerza de mentiras y coartadas, sus padres ingenian con tal de mantener el secreto familiar a salvo. 


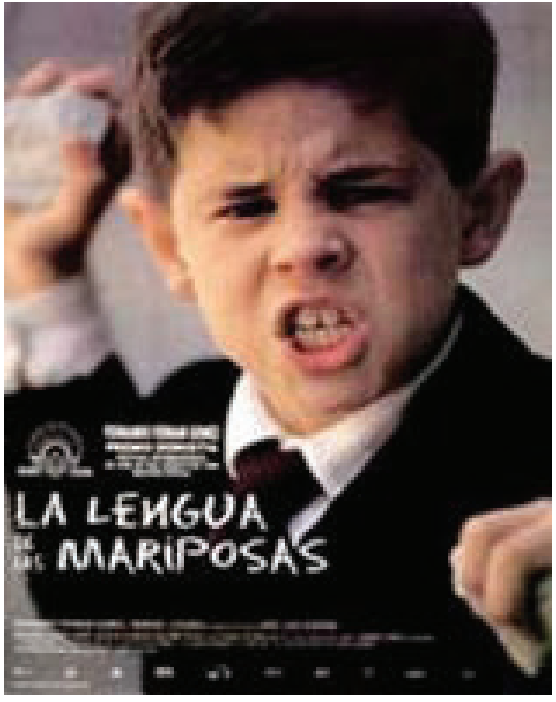

Figura 6. Cartel de La lengua de las mariposas (1999).

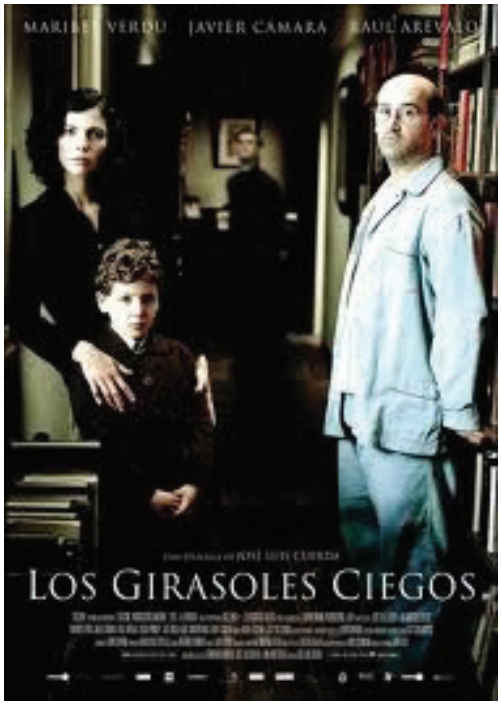

Figura 7. Cartel de Los girasoles ciegos (2009).

Otro ingrediente narrativo se centra en el papel del profesor de religión del nińo, en la figura del cura que duda de su vocación, y acosa sexualmente a la madre de su alumno. Al final, el desenlace es fatal a la hora de que intenta abusar de ella y el esposo debe salir de su escondite para defender su honra.

Esta película muestra la degradación moral de una sociedad dividida por la afrenta política y la humillación pública que significó la derrota en la guerra, pero sobre todo, deshumanizada por las estrategias de control del régimen franquista a través del estigma de exclusión que marca la vida de quien representa una amenaza latente para el franquismo, y que por lo tanto debe ser sustraído de la vida cotidiana (puesto en prisión) y eventualmente eliminado del todo.

No podemos olvidar la pléyade de imágenes infantiles que expone Canciones para después de una guerra (producido en 1971 pero exhibido públicamente hasta 1977). Ante todo, lo valioso en esta película, no es solamente la larga recopilación de imágenes visuales, y auditivas (canciones), que recrean el ambiente artístico y las modas propias del tiempo inmediato posterior del conflicto; su verdadero valor reside en que fue la primera que mostró imágenes sumamente dolorosas para aquellos que habían vivido la GCE y la represión franquista posterior. Por ejemplo, las que retratan la infinitud del hambre que azotó a los supervivientes de las zonas arrasadas por la guerra; la mención de las enfermedades que padecieron (tuberculosis, anemia, parásitos), y como colofón, 
Figura 8. Cartel de Canciones para después de una guerra (1971).

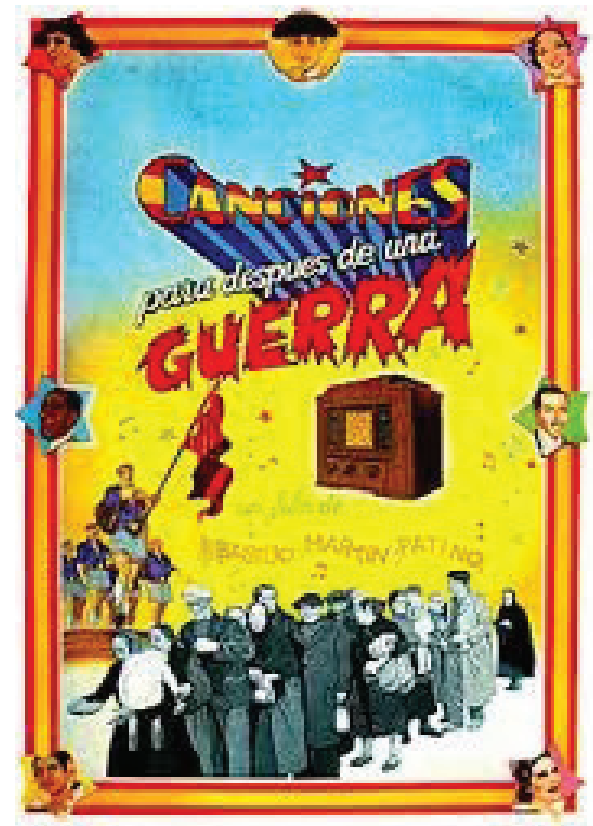

las imágenes testimoniales de las matanzas perpetradas por los sublevados en los bombardeos a las ciudades.

El director de la misma, Basilio Martín Patino (citado por Sánchez-Biosca), se refiere a su obra como: «la radiografía de aquella época, un documento descarnado de historia, sobre el recuerdo bueno o malo de aquellos años, que por muy entrańables que nos resultasen, nos han quedado como carne cicatrizada de nuestra niñez». De la película dice Sánchez-Biosca (2006a, p. 259), que permitía recuperar las imágenes fijadas en la memoria de los españoles, las cuales eran acompañadas con canciones que «en ocasiones pervertían su sentido y resultaba así mucho más evocadora que cualquier enunciado racional».

\section{INFANCIAS VULNERADAS EN EL CONFLICTO ARMADO INTERNO GUATEMALTECO}

«Contar una historia muy personal para llegar al gran público» (Argueta, 2005, p. 14), fue la meta de Luis Argueta y Justo Chang, productor y director de El silencio de Neto (1994). Con la película desearon hacer un "cine guatemalteco para el mundo». Para ello recrearon su propia infancia en la pantalla, en el turbulento 1954, año en el que la CIA orquestó una invasión a Guatemala desde Honduras, encargada a mercenarios que tuvieron la tarea de derrocar al gobierno democráticamente electo de Jacobo Arbenz 
Guzmán (hecho que consta en los documentos desclasificados que la misma CIA ha revelado).

El nombre de la cinta, es un juego de palabras que da cuenta de las secuelas del silencio que dejó la invasión. Chang (citado por Millán, 1995), explica que «en ese momento histórico el guatemalteco quedó silenciado y de ahí el juego de palabras en el título El silencio de Neto, es decir, un puro, total y 'neto' silencio en el país». Argueta opina que tal silencio es destructivo, y que hay que luchar para terminar con él. Propone el cine como medio de «reflejar la realidad, hablar, comunicarse, utilizar un lenguaje comprensible para todos, instaurar un espejo» (Millán, 1995, p. 130).

Según Argueta, su lema fue ir «de lo particular a lo universal»: contarle al mundo parte de la historia guatemalteca a través de los ojos de un niño. La propaganda hecha en la exhibición de la película rezaba: «Mientras un país pierde su inocencia, un niño lucha por hacerse escuchar», metaforizando la lucha de la naciente democracia guatemalteca, que no pudo "hacerse escuchar», es decir, consolidarse (Argueta, 2005, p. 50).

Neto, un niño en las puertas de la adolescencia, comparte los eventos propios de su edad con los sucesos que dieron al traste con el gobierno de Arbenz, el segundo gobierno revolucionario de la llamada "primavera guatemalteca» (1944-1954).

Consecuencia directa de dicho contragolpe, fue la guerra de 36 años que sumió al país en el silencio. El tejido social de la sociedad guatemalteca fue seriamente fragmentado a raíz de ello. A nivel metafórico, la película da cuenta de la incomunicación vivida en las familias, lo cual puede ser producto de la profunda desconfianza que impide sanas relaciones interpersonales en un ambiente de postguerra. Nery Villanueva, profesor de la Universidad de Alabama, estudia las relaciones en el interior del filme: «Los problemas entre padre e hijo son el producto de la incomunicación. No se puede depositar confianza en alguien que no se conoce. La confianza o desconfianza surge a través de las relaciones interpersonales. Desconfiar de alguien sin conocerle es prejuzgarlo». Según él, el padre desconfía de Neto porque no se ha "tomado el tiempo" para conocerlo (Argueta, 2005, p. 38).

Voces inocentes (1995), relata las experiencias de dos nińos hermanos, y cómo la guerra influye en sus condiciones de pobreza y de falta de esperanza en el futuro. Sobre todo se centra en presentar la ruptura de la normalidad en un pueblo del interior, puesto que los nińos se ven rodeados del clima de guerra, a partir de las requisas de los soldados gubernamentales, y de la constante interrupción de sus actividades cotidianas por el conflicto: los cierres de las escuelas, la intranquilidad de caminar por las calles repletas de militares, y las constantes conversaciones familiares respecto de la inseguridad y el peligro de la situación. 


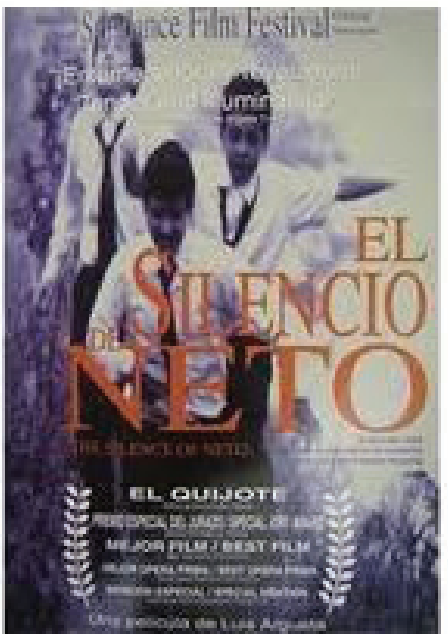

Figura 9. Cartel de El Silencio de Neto (1994).

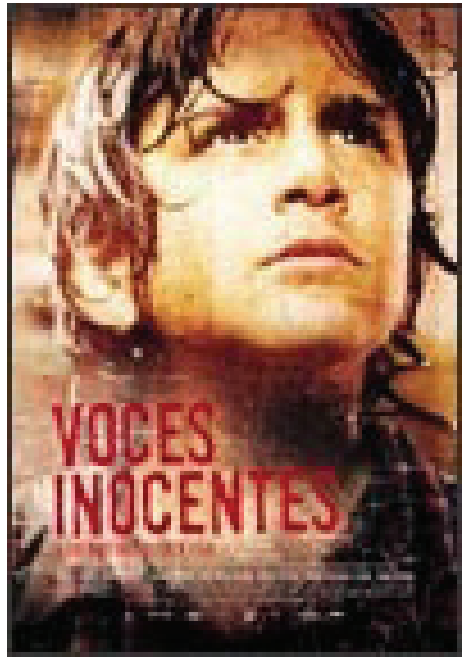

Figura 10. Cartel de Voces inocentes (1995).

Las actuaciones son muy acertadas en cuanto a dar credibilidad al drama vivido en el seno de una familia de clase media, que vive con el temor constante de ser víctima de las escaramuzas entre gobierno y guerrilla, o bien verse obligada a renunciar a los más preciado de sus pertenencias: los nińos varones que fueron reclutados por igual, tanto por la guerrilla, como por el ejército regular.

Lo interesante de la película es que describe las estrategias autoritarias mediante las cuales los gobiernos centroamericanos lograron hacer frente a las guerras de guerrillas: encontrar soplones, o el reclutamiento forzoso de jóvenes del interior para engrosar las filas del ejército. Además retrata las condiciones de pobreza que fueron el caldo de cultivo para que los sectores rebeldes de la población buscaran cambiar el régimen por la fuerza de las armas.

Aunque Voces Inocentes trata el conflicto armado salvadoreño, se incluye en este estudio por la cercanía de toda índole con la realidad de la infancia guatemalteca. La película fue filmada en México, con actores y locaciones mexicanos, por lo que podemos decir que representa el sufrimiento de pueblos hermanos que se debatieron en guerras fratricidas en la década de los 80 . 


\section{CONCLUSIONES}

En el cine que toca las guerras civiles de Espańa y Guatemala, encontramos varias películas que toman la figura de la infancia como protagonista principal. A manera de ejemplo, podemos decir que, en el caso español, La lengua de las mariposas, el niño cumple el papel de un alumno que llega por vez primera a la escuela, mostrando sus miedos, su angustia de verse separado de su ser más querido (la madre), a cambio del cuidado del personal docente. En este caso la figura del profesor asume la responsabilidad de orientarlo de manera exitosa en el camino de hacerlo una persona con los conocimientos adecuados, pero también con la responsabilidad ambiental y ética necesaria para la convivencia social.

En el caso guatemalteco, el ejemplo lo constituye el preadolescente protagonista de El silencio de Neto, aunque mantiene aún la inocencia de nińo, se muestra atento a los movimientos políticos de los mayores, y sobre todo, es testigo y víctima de la angustia de un mundo adulto lleno de prohibiciones, de reglas a seguir y de conductas preconcebidas que rayan entre lo bueno y lo malo. Esto lo percibe Neto a raíz de las discusiones entre su padre, quien representa los tabúes y cánones rígidos sociales, y que se opone a la figura de su tío, libre pensador y amante de la causa democrática del gobierno revolucionario de Arbenz.

Los protagonistas de Los niños de Rusia, y el Otro árbol de Guernica, encarnan la tragedia bélica de la Guerra Civil espańola, en donde miles de nińos tuvieron que salvar la vida refugiándose en tierras extranjeras. Todo ello a costa del abandono del nido familiar, e incluso del desarraigo en tierras ajenas, que perduró durante toda su vida. Esto se hace evidente en el caso de Los niños de Rusia, pues por haber vivido mucho tiempo fuera, los refugiados no solamente sufrieron durante el conflicto, sino que a su regreso a España se sintieron «extranjeros en su propia tierra».

En lo que se refiere al problema migratorio, como consecuencia del Conflicto Armado guatemalteco, igualmente se movieron miles de personas hacia lugares ajenos al lugar de origen, y la mayoría de los niños que nacieron en campos de refugiados de México, Bolivia, y otros países hermanos que brindaron asilo a los perseguidos por el conflicto, han retornado al suelo patrio pero en condiciones precarias, que no auguran una inserción digna en una sociedad globalizada. Esta problemática se hace evidente en películas tales como La hija del puma.

Podemos concluir que la revisión de las vivencias y experiencias infantiles que el cine recrea en películas referentes a las guerras civiles de Guatemala y España, puede constituir un importante referente a seguir por la Escuela, en su papel de instructora y formadora de las nuevas generaciones. 
En lo que respecta a la reconstrucción de la memoria y los hechos históricos, encontramos numerosos expertos que recomiendan su utilización en las aulas, sobre todo por las características del cine en cuanto a integrar diferentes disciplinas, y a su capacidad de, tal y como lo dice de la Torre (2005), lograr aquellos «estímulos multisensoriales lo más cercanamente posible a como son percibidos en la realidad (simulación)». Los ejemplos de las películas analizadas en el presente estudio, corroboran dichas opiniones, por cuanto revelan hechos del pasado que si no fuera porque la industria del cine acude a ellos, sería muy difícil que otro tipo de materiales (escolares o no), tuvieran la capacidad de recrearlos con tanto detalle y fuerza evocativa.

\section{FUENTES REFERENCIALES}

Amar, Victor (2000). «La alfabetización audiovisual a través de la educación con el cine». Comunicar: Revista Cientifica Iberoamericana de Comunicación y Educación, No 15. Huelva: Colectivo Andaluz para la educación en medios de comunicación.

Argueta, Luis (2005). El silencio de Neto, guión y artículos afines. Guatemala: Editorial Universitaria, USAC.

Crusells, Magí (2000). La Guerra Civil Española: cine y propaganda. Barcelona: Ariel.

Crusells, Magí (2006). Cine y Guerra Civil Española, imágenes para la memoria. Madrid: Ediciones JC.

De los Reyes, José (2011) Curso: Historia, Cine y Escuela (entrevista personal efectuada el 19 de julio de 2011). Universidad Autónoma de Madrid.

Ferro, Marc (1995). Historia Contemporánea y cine. Barcelona: Ariel.

Ferro, Marc (2008). El cine, una visión de la historia. Madrid: Akal.

García, Francisco (2000a). La representación del niño en los medios de comunicación. Madrid: Huerga y Fierro.

García, Francisco (2000b). La imagen del niño en los medios de comunicación. Madrid: Huerga y Fierro.

Gubern, Román (1986). 1936-1939: La guerra de España en la pantalla.Madrid: Filmoteca Española.

Gubern, Román (2005). «La guerra vista por el cine». En: Revista Letra Internacional, No 87. Editorial Pablo Iglesias. 
Ibánez, Juan y Anania, Francesca (2010). Memoria histórica e identidad en cine y televisión. Zamora: Comunicación Social, ediciones y publicaciones.

Millán, Francisco (1995). La hija del puma, cine con rostro indígena. Escuela de Ciencias de la Comunicación, Universidad de San Carlos de Guatemala.

Monterde, José (1986). Cine, historia y enseñanza. Barcelona: Laia.

Payán, Javier (2006). Las cien mejores películas sobre la Guerra Civil Española. Madrid: Cacitel.

Payán, Miguel (1993). El cine español de los 90. Madrid: Ediciones JC.

Rosenstone, Robert (1995). Revisioning history film \& the construction of a new past. New Jersey: Princenton University Press Studies in Culture.

Rosenstone, Robert (1997). El pasado en imágenes, el desafio del cine a nuestra idea de la historia. Barcelona: Ariel.

Sánchez-Biosca, Vicente (2006a). Cine y Guerra Civil Española, del mito a la memoria. Madrid: Alianza Editorial.

Sánchez-Biosca, Vicente (2006b). Cine de historia, cine de memoria. La representación y sus límites. Madrid: Cátedra.

Yela, Otto (2006). El cine como laboratorio social: La reconstrucción de eventos históricos en el aula a partir de una hermenéutica audiovisual. Trabajo de Investigación Tutelado. Doctorado en Desarrollo Psicológico, Aprendizaje y Educación, Perspectivas Contemporáneas. Universidad de Alcalá. 